\title{
RESEARCH
}

Open Access

\section{$n$-3 PUFA added to high-fat diets affect differently adiposity and inflammation when carried by phospholipids or triacylglycerols in mice}

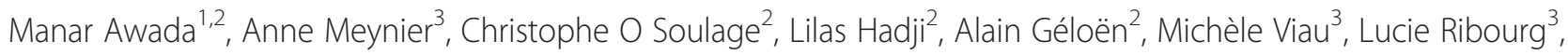
Berengère Benoit ${ }^{2,5}$, Cyrille Debard ${ }^{4}$, Michel Guichardant ${ }^{2}$, Michel Lagarde ${ }^{2}$, Claude Genot ${ }^{3}$ and Marie-Caroline Michalski ${ }^{1,2,5,6^{*}}$

\begin{abstract}
Background: Dietary intake of $n-3$ polyunsaturated fatty acids (PUFA) is primarily recognized to protect against cardiovascular diseases, cognitive dysfunctions and the onset of obesity and associated metabolic disorders. However, some of their properties such as bioavailability can depend on their chemical carriers. The objective of our study was to test the hypothesis that the nature of n-3 PUFA carrier results in different metabolic effects related to adiposity, oxidative stress and inflammation.

Methods: 4 groups of C57BL/6 mice were fed for 8 weeks low fat (LF) diet or high-fat (HF, 20\%) diets. Two groups of high-fat diets were supplemented with long-chain $n-3$ PUFA either incorporated in the form of phospholipids

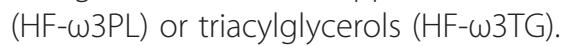

Results: Both HF- $\omega 3 \mathrm{PL}$ and HF- $\omega 3 \mathrm{TG}$ diets reduced the plasma concentrations of (i) inflammatory markers such as monocyte chemoattractant protein-1 (MCP-1) and interleukin 6 (IL-6), (ii) leptin and (iii) 4-hydroxy-2-nonenal (4HNE), a marker of $n-6$ PUFA-derived oxidative stress compared with the control HF diet. Moreover, in both HF- $\omega 3 \mathrm{PL}$ and HF- $\omega 3$ TG groups, MCP-1 and IL-6 gene expressions were decreased in epididymal adipose tissue and the mRNA level of gastrointestinal glutathione peroxidase GPx2, an antioxidant enzyme, was decreased in the jejunum compared with the control HF diet. The type of $n-3$ PUFA carrier affected other outcomes. The phospholipid form of $n-3$ PUFA increased the level of tocopherols in epididymal adipose tissue compared with HF- 13 TG and resulted in smaller adipocytes than the two others HF groups. Adipocytes in the HF-w3PL and LF groups were similar in size distribution.
\end{abstract}

Conclusion: Supplementation of mice diet with long-chain n-3 PUFA during long-term consumption of high-fat diets had the same lowering effects on inflammation regardless of triacyglycerol or phospholipid carrier, whereas the location of these fatty acids on a PL carrier had a major effect on decreasing the size of adipocytes that was not observed with the triacyglycerol carrier. Altogether, these results would support the development functional foods containing LC n-3 PUFA in the form of PL in order to prevent some deleterious outcomes associated with the development of obesity.

Keywords: $n$-3 PUFA, Phospholipid, Triacylglycerol, High-fat diet, Inflammation, Oxidative stress, Adipose tissue

\footnotetext{
* Correspondence: marie-caroline.michalski@insa-lyon.fr

${ }^{1}$ INRA, U1362, CarMeN, Villeurbanne F-69621, France

${ }^{2}$ INSA-Lyon, IMBL, Villeurbanne F-69621, France

Full list of author information is available at the end of the article
} 


\section{Background}

Chronic inflammation and oxidative stress are recognized as major factors involved in the pathogenesis of several current metabolic diseases such as obesity, type 2 diabetes and cardiovascular diseases (CVD) [1-3]. Elevated levels of pro-inflammatory cytokines and chemokines, such as interleukins (IL) and monocyte chemotactic protein-1 (MCP-1), are hallmarks of the metabolic syndrome [1,2]. It is now established that white adipose tissue (WAT) is not only an energystorage tissue but also an endocrine organ that secretes various bioactive molecules namely "adipokines" including adiponectin, leptin, IL-6 and MCP-1, [4]. These molecules have a key role in the regulation of systemic and energy metabolism. Indeed, dysregulated production of these adipokines due to WAT dysfunction and excess adiposity can contribute to the pathogenesis of obesity and insulin resistance [5]. High-fat intake has been repeatedly shown to play a significant part in the obesityassociated low grade chronic inflammation, which is characterized in human and mice by macrophage infiltration in WAT [6-9].

In this context, dietary supplementation with longchain $n-3$ polyunsaturated fatty acids (LC $n-3$ PUFA), in particular docosahexaenoic acid (DHA; 22:6n-3) and eicosapentaenoic acid (EPA; 20:5 n-3) presents a variety of health benefits. These LC $n-3$ PUFA are known to be protective by reducing inflammation in both blood and WAT $[6,10,11]$, improving lipid metabolism [12], decreasing risk of CVD [13,14] and several neurodegerenative diseases $[15,16]$. Therefore, nutritional recommendations of $250 \mathrm{mg} /$ day of EPA/DHA have been established in Western societies for $n$-3 PUFA intake, to achieve nutrient adequacy and lower $n-6 / n-3$ PUFA ratio [17].

Dietary EPA and DHA are provided mostly by fatty fish, where they are mainly esterified in triacylglycerols (TG). In other sources such as krill, the major proportion of these LC $n$-3 PUFA is esterified in phospholipids (PL). Of note, compared with fish oil, krill oil contains the same amount of DHA but a greater proportion of EPA [18]. The latter is a major precursor of antiinflammatory eicosanoids [19]. Some authors have compared the potential effects of different LC $n$-3 PUFA formulations on lipid metabolism. The supplementation of LC n-3 PUFA in the form of PL would exert superior biological and nutritional functions compared to TG. This would include (i) anti-inflammatory actions [20,21] and antioxidant activities on the brain lipids [22], (ii) improved memory and learning [23], (iii) reduced blood and tissue lipids [24-26], (iv) increased bioavailability of EPA and DHA in plasma $[27,28]$ and (v) tendency to reduce obesity [21]. In humans, the effects of PL-bound LC $n$-3 PUFA provided by krill oil on plasma lipids were similar to those of TG-bound LC $n-3$ PUFA from fish oil but at lower dose of LC $n-3$ PUFA [27]. In the rodent studies, the amount of LC $n-3$ PUFA in the diets were usually high, i.e. $\sim 8-15 \%$ of total fats $[21,26,29]$.

To date, available data are insufficient to assess whether the supplementation of Western-type high-fat (HF) diets with LC $n-3$ PUFA carried either by TG or by PL can make any difference in the metabolic outcomes, with an aim to prevent or treat metabolic disorders.

The aim of the present study was to test the hypothesis that long-term intake of nutritional amounts of $n-3$ PUFA in realistic HF diets could exert different effects according to the PL or TG carrier on (i) the development of adiposity and (ii) associated oxidative stress and inflammation.

\section{Methods}

\section{Materials}

Omegavie $^{\circledR}$ Tuna oil 25 DHA flavorless was provided by Polaris (Pleuven, France) as a source of triacylglycerol rich in LC $n-3$ fatty acids. A lecithin rich in DHA was enzymatically synthesized by Polaris (Pleuven, France) and further purified by precipitation with cold acetone to eliminate all traces of triacylglycerols and ethyl esters [30]. As shown by HPLC paired with evaporative lightscattering detector and external calibration curves, PLDHA was composed of lysophosphatidylcholine (lysoPC: $49.2 \pm 0.7$ wt\%), phosphatidylcholine (PC; $33.5 \pm 0.4$ wt\%), phosphatidylinositol (PI; $9.0 \pm 0.3$ wt\%), phosphatidylethanolamine (PE: $4.8 \pm 0.7 \mathrm{wt} \%)$ and sphingomyelin (3.5 $\pm 0.2 \mathrm{wt} \%$ ). Lard was supplied by Celys (Rezé, France) and kiwi seed oil, as additional source of alpha-linolenic acid, by Polaris (Pleuven, France). Sunflower oil (Lesieur ${ }^{\circledR}$ ) was purchased from a local supermarket and oleic sunflower oil from Olvéa (Marseille, France). The vegetable lecithin rich in linoleic acid 18:2 n-6 (PL-LA) was sold by Lipoid (Ludwigshafen, Germany) and was composed exclusively of phosphatidylcholine and antioxidants (no TAG).

\section{Preparation of lipid for mice diets}

Low fat (LF), HF and the two HF lipid blends containing LC $n$-3 PUFA in the form of PL or TG were prepared at the labscale. DHA and, in lower amount, EPA were sup-

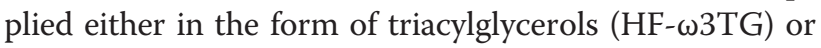
phospholipids (HF- $\omega \mathrm{PL}$ ). The fatty acid compositions of both the tuna oil and the lecithin rich DHA product are reported in Additional file 1. The four blends were prepared by direct mixing of the different oils and fat sources, including the lard in the proportions indicated in Table 1. Then they were stored under a flux of nitrogen at $-20^{\circ} \mathrm{C}$ and sent to SAFE (Augy, France) for preparing the mice diets. The composition of the four diets is reported Table 1 . HF- $\omega 3 \mathrm{TG}$ and HF- $\omega 3 \mathrm{PL}$ are the diets that served as unoxidized $n-3$ diet controls in our other study about the impact of PUFA oxidation [30]. 
Table 1 Formulation of the experimental diets

\begin{tabular}{lcccc}
\hline High-fat containing $\mathbf{n}-\mathbf{3}$ PUFA as & LF & HF & HF- $\boldsymbol{\omega} 3 \mathbf{P L}$ & HF- $\boldsymbol{\omega} \mathbf{3 T G}$ \\
\hline Ingredient $(\mathbf{g} / \mathbf{1 0 0} \mathbf{g})$ & & & & \\
\hline Lipid mixture & 5 & 20 & 20 & 20 \\
Among which: & & & & \\
$\quad$ Lard & 2 & 18.10 & 18.10 & 18.06 \\
Sunflower oil & 0.64 & 1.1 & 0.6 & 0.2 \\
Oleic sunflower & 1.27 & 0.0 & 0.4 & - \\
Kiwi seed oil & 0.29 & 0.0 & 0.1 & 0.02 \\
Tuna oil & - & - & - & 0.9 \\
Phospholipids & & & & \\
$\quad$ PL-DHA & - & - & 0.8 & - \\
$\quad$ Lecithin PL-LA & 0.8 & 0.8 & - & 0.8 \\
Corn starch & 54 & 39 & 39 & 39 \\
Casein & 20 & 20 & 20 & 20 \\
Sucrose & 10 & 10 & 10 & 10 \\
Pure cellulose & 5 & 5 & 5 & 5 \\
Vitamin mixture & 5 & 5 & 5 & 5 \\
Mineral mixture & 1 & 1 & 1 & 1 \\
Tocopherols & 19.1 & 15.7 & 15.7 & 15.7 \\
Energy content (kJ/g) & 57.6 & 34.1 & 34.1 & 34.1 \\
\hline Energy\% & 12.8 & 41.5 & 41.5 & 41.5 \\
\hline Protein & 0.000 & 0.084 & 0.099 & 0.092 \\
Carbohydrates & 18.14 & 18.14 & 18.14 \\
\hline Lipids & & & & \\
\hline
\end{tabular}

${ }^{a}$ Considering the difference observed in tocopherols in lipid mixtures, which can affect their metabolic impact [31], care was taken to supplement lipid mixtures with a-tocopherol during formulation to achieve iso-tocopherol diets.

\section{Animals and diets}

Male C57BL/6 mice (8 wk, $20 \mathrm{~g}$ ) from Janvier SA (Le Genest Saint-Isle, France) were housed in a temperaturecontrolled room $\left(22^{\circ} \mathrm{C}\right)$ with a $12 \mathrm{~h}$ light $/ 12 \mathrm{~h}$ dark cycles. After 2 weeks of chow diet, mice were randomly divided into four groups fed one of the four following diets for 8 weeks: LF, HF, HF- $\omega 3$ TG and HF- $\omega 3$ PL diets. Animal experiments were performed under the authorization n69-266-0501 (Direction Départementale des Services Vétérinaires du Rhône, France). All experiments were carried out in compliance with the French Ministry of Agriculture guidelines ( $\left.\mathrm{n}^{\circ} 87-848\right)$ and the E.U. Council Directive for the Care and Use of Laboratory Animals of November 24th, 1986 (86/609/EEC), in conformity with the Public Health Service (PHS) Policy on Humane Care and Use of Laboratory Animals. COS holds a special licence $\left(n^{\circ} 69266257\right)$ to experiment on living vertebrates issued by the French Ministry of Agriculture and Veterinary Service Department. Body weight was measured twice a week and food intake was measured weekly. After
8 weeks, mice were euthanized by intraperitoneal (IP) injection of sodium pentobarbital and blood was collected by cardiac puncture under pyrogen-free conditions on heparin-containing tubes. Plasma, liver, WAT, muscles, duodenum and jejunum were collected. For analysis of 4-hydroxy-2-alkenals, due to plasma volume constraints, 3 pools of $300 \mu \mathrm{L}$ obtained from 3 mice (100 $\mu \mathrm{L}$ per mice) were used for each group.

\section{4-Hydroxy-2-alkenals: derivatization, analysis and quantification}

4-hydroxy-2-alkenals were derivatized from $300 \mu \mathrm{l}$ of plasma as described previously [32]. Deuterated 4hydroxy-2-nonenal (4-HNE) and 4-hydroxy-2-hexenal (4-HHE) (20 ng) used as internal standards were added to the samples. Briefly, they were treated with O-2,3,4,5,6-pentafluorobenzyl hydroxylamine hydrochloride. After acidification with $\mathrm{H}_{2} \mathrm{SO}_{4}$, pentafluorobenzyloxime derivatives were extracted with methanol and hexane. The hydroxyl group was then converted into trimethylsilylether after an overnight treatment with N,Obis(trimethylsilyl)trifluoroacetamide at room temperature. The pentafluorobenzyloxime trimethylsilylether derivatives of 4-HHE (O-PFB-TMS-4-HHE) and 4-HNE (O-PFBTMS-4-HNE) were then analyzed by GC-MS using negative ion chemical ionization (NICI) mode on a HewlettPackard quadripole mass spectrometer interfaced [32] with a Hewlett-Packard gas chromatograph (Les Ullis, France). For the determination of 4-hydroxy-2-alkenals in liver, the tissue was firstly minced in liquid nitrogen with PIPES, then centrifuged and the supernatant treated as previously described. Regarding WAT, a protocol has been adapted to the extraction and derivatization of 4-hydroxy-2-alkenals in lipophilic media. Briefly the o-pentafluorobenzyl hydroxylamine was prepared by dilution in hexane containing pure triethylamine leading to the formation of a precipitate, which was removed. Oxime derivatives were then prepared and extracted with hexane. Lipids were remove by solid phase extraction on silica cartridge, and the oxime derivatives were eluated with hexane/diethyl ether $(50 / 50, \mathrm{vol} / \mathrm{vol})$. The second derivatization (silylation) was achieved as previously described. The method allowed the quantification of free 4-HHE and 4-HNE.

sCD14, LBP, IL-6, MCP-1, leptin, adiponectin, insulin and glucose measurements

MCP-1, IL-6 (Clinisciences, France), sCD14, LBP (Enzo Life Sciences), leptin, adiponectin (SpiBio, Montigny Le Bretonneux, France) and insulin (Crystal Chem Inc., USA) plasma levels were assayed by ELISA kits according to the manufacturer's instructions. Blood glucose levels were measured on animals in mouse-tail blood using a glucometer (Accu-Chek ${ }^{\circledR}$, Roche, France). 


\section{Plasma triacylglycerols and NEFA measurements}

Plasma triacyglycerols (TAG) were measured with the triglyceride PAP kit (BioMérieux France) as previously described [33]. Plasma TAG concentration was calculated by subtracting the free glycerol in plasma measured with the glycerol UV-method (R-Biopharm/Boehringer, Mannheim, Germany). Plasma NEFA was measured using NEFA-C kit (Wako Chemicals, Neuss, Germany).

\section{Fatty acid analysis}

Total lipids were extracted from $35 \mu \mathrm{L}$ of plasma as described previously [33] and from tissues according to Folch et al. [34]. The organic phase (solvent) was evaporated under $\mathrm{N}_{2}$ and total fatty acids were transesterified using boron trifluoride in methanol $\left(\mathrm{BF}_{3} /\right.$ methanol) and in the presence of heptadecanoic acid (C17:0, Sigma, France) as an internal standard [33]. The FA methyl esters were then analyzed by GC using a DELSI instrument model DI 200 equipped with a fused silica capillary SP-2380 column $(60 \mathrm{~m} \times 0.22 \mathrm{~mm})$.

\section{Quantification of tocopherols}

Tocopherols in epipidymal WAT (eWAT) and retroperitoneal WAT (rWAT) were quantified without saponification according to a method described by [35]. An aliquot of lipid extract was dried under $\mathrm{N}_{2}$, then solubilized in $\mathrm{n}$-hexane and analyzed by HPLC paired with a fluorimeter detector $(\lambda \mathrm{ex}=295 \mathrm{~nm}$ and $\lambda \mathrm{em}=$ $330 \mathrm{~nm}$ ). Separation of the different isomers of tocopherols and tocotrienols was achieved on a polar column (Acclaim Polar advantage II, Dionex, $3 \mu \mathrm{m} ; 250$ $\times 3 \mathrm{~mm}$ ) in isocratic mode at $0.5 \mathrm{ml} / \mathrm{min}$ with hexane/ methyl-terbutyl-ether $90 / 10$, vol/vol. The quantification was realized by comparison of the peak areas with calibration curves performed with external standard solutions of $\alpha, \gamma, \beta$ and $\delta$ tocopherols (Calbiochem, tocopherol set) and $\gamma$ tocotrienol (Sigma, France). An aliquot of each diet was saponified for $30 \mathrm{~min}$ at $70^{\circ} \mathrm{C}$ in a mixture containing potassium hydroxide $(50 \% \mathrm{w} / \mathrm{vol}$ in water), pyrogallol in ethanol $(1 \% \mathrm{w} / \mathrm{vol})$. Tocopherols were extracted with hexane containing $0.005 \%$ (w/vol) of BHT. After centrifugation and washing, the organic phase was mixed. The solvent was removed under vacuum, and then under a stream of nitrogen. Tocopherols were finally dissolved in $n$-hexane and then quantified as described previously.

\section{Cellularity study: measurement of adipocyte size and number}

Preparation of adipose tissue for determination of cell size was performed essentially as described previously [36]. Briefly, 30-40 mg of eWAT or rWAT was immediately fixed in osmium tetroxide for 96 hours at room temperature. After washing, adipose cell-size distribution was then assessed using a Beckman Coulter Multisizer IV (Beckman Coulter) with a $400 \mu \mathrm{m}$ aperture. The range of cell-sizes that can effectively be measured using this aperture is $20-240 \mu \mathrm{m}$. The instrument was set to count 1000 particles per run, and the fixed-cell suspension was diluted so that coincident counting was less than $10 \%$. After collection of pulse sizes, the data were expressed as particle diameters and displayed as histograms of counts against diameter using linear bins and a linear scale for the cell diameter. Cellsize distributions were drawn from measurement of at least 12000 cell diameters per animal. Mean cell weight was calculated as measured Cell volume $\times$ TG density (0.9); cell number were calculated as Cell weight/WAT mass (eWAT or rWAT).

\section{Quantitative PCR analysis}

Total RNA was extracted from $50 \mathrm{mg}$ of duodenum and jejunum of mice using the NucleoSpin ${ }^{\circledR}$ RNA/Protein kit (Macherey Nagel, Duren, Germany), and from $50 \mathrm{mg}$ of eWAT or rWAT with TRIzol (Invitrogen, Eragny, France). cDNAs were synthesized from $1 \mu \mathrm{g}$ of total RNA in the presence of 100 units of Superscript II (Invitrogen, France) with a mixture of random hexamers and oligo (dt) primers (Promega, Charbonnières, France). The amount of target mRNAs was measured by RT, followed by real-time PCR, using a Rotor-Gene Q (Qiagen, France). The amount of target mRNAs was measured by RT, followed by real-time PCR, using a Rotor-Gene Q (Qiagen, France). Primer sequence and RT-quantitative PCR conditions are available upon request (cyrille.debard@univ-lyon1.fr). Hypoxanthine guanine phosphoribosyl transferase (HPRT) mRNA was used to normalize data of duodenum, jejunum and WAT of mice.

\section{Statistical analysis}

All data are presented as means \pm SEM and were analysed using Statview 5.0 software (Abacus Concept, Berkeley). One-way ANOVA followed by Fisher PLSD was used to compare the four groups. Differences were considered significant at $P<0.05$.

\section{Results}

\section{Diet compositions}

Table 2 shows that we succeeded in producing diets equilibrated in terms of $n-3$ PUFA supplies and $n-6 / n-3$ ratios, with LC $n-3$ PUFA in the form of PL or TG. Importantly, HF- $\omega 3$ TG diet, HF diet and LF diet also contained PL in the form of PL-LA lecithin, so that effects of PL- $\omega 3$ can be attributed to the molecular form of LC $n-3$ PUFA in the diet, not to the presence of phospholipids.

The HF- $\omega 3$ PL diet contained slightly less $n-3$ PUFA than the HF- $\omega 3$ TG diet, as frequently found in dietary $n-3$ 
Table 2 Fatty acid composition in the diets

\begin{tabular}{|c|c|c|c|c|}
\hline FA mg/g diet & LF & HF & HF-w3PL & 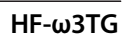 \\
\hline$\overline{\text { SFA }}$ & $11.3 \pm 1.6$ & $71 \pm 12^{\$}$ & $64 \pm 1^{\$}$ & $66 \pm 5^{5}$ \\
\hline MUFA & $24 \pm 6$ & $82 \pm 14^{\$}$ & $76 \pm 1^{\$}$ & $72 \pm 5^{5}$ \\
\hline$n-6$ PUFA & $12 \pm 2$ & $29 \pm 5^{\$}$ & $21 \pm 1^{\$}$ & $21 \pm 1^{\$}$ \\
\hline$n-3$ PUFA & $2.1 \pm 0.2$ & $2.0 \pm 0.4$ & $2.8 \pm 0.2^{5^{*}}$ & $3.9 \pm 0.1^{\$^{*}}$ \\
\hline Among which $18: 3 n-3$ & $2.1 \pm 0.2$ & $2.0 \pm 0.4$ & $2.0 \pm 0.1$ & $1.9 \pm 0.1$ \\
\hline $20: 5 n-3$ & - & - & $0.2 \pm 0.0^{\xi^{*}}$ & $0.4 \pm 0.2^{2^{*}}$ \\
\hline $22: 6 n-3$ & - & - & $2.8 \pm 0.2^{\xi^{*}}$ & $3.9 \pm 0.2^{5^{*}}$ \\
\hline Total PUFA & $13.8 \pm 2.3$ & $30.4 \pm 5^{5}$ & $23.7 \pm 0.4^{\$}$ & $25.0 \pm 1.4^{\$}$ \\
\hline$n-6 / n-3$ ratio & $5.4 \pm 0.4^{*}$ & $14.3 \pm 0.3$ & $7.7 \pm 0.5^{*}$ & $5.4 \pm 0.2^{*}$ \\
\hline Total FA & $49 \pm 9$ & $184 \pm 31^{\$}$ & $163 \pm 2^{\$}$ & $162 \pm 11^{\$}$ \\
\hline a-tocopherol ( $\mu \mathrm{g} / \mathrm{g}$ chow) & $185 \pm 6$ & $219 \pm 4$ & $201 \pm 1$ & $207 \pm 18$ \\
\hline
\end{tabular}

$\left({ }^{*} \mathrm{P}<0.05\right.$ vs HF); $\left({ }^{5} \mathrm{P}<0.05\right.$ vs $\left.\mathrm{LF}\right),\left({ }^{5} \mathrm{P}<0.05\right.$ vs HF-w3TG). ANOVA followed by Fisher test. Data are mean \pm SEM for $n=3$. Abbreviations: $F A$, fatty acids; MUFA, monounsaturated fatty acids; SFA, saturated fatty acids.

PUFA sources. In $n-3$ PUFA enriched diets, $n$-3 PUFA contents and $n-6 / n-3$ ratios were consistent with dietary recommendations, whereas $n-6 / n-3$ ratio was nearly 15 in HF diet as observed in human Western diets.

\section{PL- $\omega 3$ and TG- $\omega 3$ in high-fat diet modify biometric parameters}

As shown in Table 3, the supplementation of HF diets with LC $n-3$ PUFA decreased the body weight gain in HF- $\omega 3 \mathrm{PL}$ fed mice compared to HF mice but not in HF- $\omega 3$ TG mice. Liver weight was significantly lower in mice

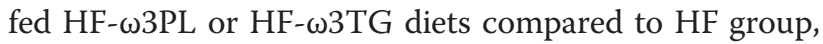
and even lower than LF group regarding HF- $\omega 3 \mathrm{PL}$. White adipose tissue weight (total of retroperitoneal, epididymal and subcutaneous adipose tissues) was also lower in HF- $\omega 3 \mathrm{PL}$ group than in HF group but no significant difference was observed between HF- $\omega 3 \mathrm{PL}$ and HF- $\omega 3$ TG groups. However, the lean mass estimated by the weight of gastrocnemius muscle was not different between the groups (Table 3 ).

Energy intake was evaluated during the 8 weeks of feeding trial. Table 3 shows that it was higher in the three HF groups than in LF group. However, results did not show any difference between HF- $\omega 3 \mathrm{PL}$ and HF$\omega 3$ TG groups. After 8 weeks feeding, free fatty acid and triacyglycerol concentrations were lower $(P<0.05)$ in the plasma of the three groups of mice fed HF diets, regardless of supplementation with $n$-3 PUFA, than in LF group (Table 3). Plasma insulin and glucose levels did not differ among the groups. Neither plasma free fatty acid nor triacyglycerol concentrations were significantly different between the three groups of mice fed HF diets. Hepatic lipid accumulation was similar among groups.

Fatty acid composition in plasma and tissues reflects the enrichment with PL- $\omega 3$ and TG- $\omega 3$ in the high-fat diets Fatty acid composition of total plasma, liver and WAT were characterized to investigate whether long-term

Table 3 Morphologic parameters, food intake and plasma lipid concentrations of mice

\begin{tabular}{|c|c|c|c|c|}
\hline \multirow[t]{2}{*}{ Morphologic parameters } & \multicolumn{4}{|c|}{ Mice groups according to dietary lipids } \\
\hline & LF & $\mathrm{HF}$ & HF-w3PL & HF-w3TG \\
\hline \multicolumn{5}{|l|}{ Biometric data } \\
\hline Initial Body weight (g) & $24.1 \pm 0.4$ & $24.2 \pm 0.3$ & $23.9 \pm 0.3$ & $24.5 \pm 0.3$ \\
\hline Body weight gain (g) & $4.1 \pm 0.1$ & $4.2 \pm 0.5$ & $3.1 \pm 0.1^{* \$}$ & $3.7 \pm 0.3$ \\
\hline Energy Intake (kJ/mouse/d) & $39.1 \pm 0.9$ & $68.9 \pm 0.3^{\$}$ & $60.2 \pm 1.3^{\$}$ & $59.8 \pm 1.3^{\$}$ \\
\hline Liver weight (g) & $1.39 \pm 0.03$ & $1.36 \pm 0.03$ & $1.21 \pm 0.04^{* \$}$ & $1.27 \pm 0.04^{*}$ \\
\hline WAT weight (g) & $0.84 \pm 0.05$ & $1.03 \pm 0.12$ & $0.72 \pm 0.05^{*}$ & $0.93 \pm 0.11$ \\
\hline Gastrocnemius (g) & $0.16 \pm 0.0$ & $0.16 \pm 0.0$ & $0.16 \pm 0.0$ & $0.15 \pm 0.0$ \\
\hline \multicolumn{5}{|l|}{ Plasma lipids } \\
\hline TAG (mM) & $0.89 \pm 0.06$ & $0.66 \pm 0.09^{\$}$ & $0.64 \pm 0.04^{\$}$ & $0.57 \pm 0.04^{\$}$ \\
\hline NEFA (mM) & $0.62 \pm 0.5$ & $0.35 \pm 0.02^{\$}$ & $0.27 \pm 0.01^{\$}$ & $0.37 \pm 0.02^{5}$ \\
\hline Glucose (mmol/L) & $9.1 \pm 0.8$ & $8.6 \pm 0.5$ & $9.4 \pm 0.9$ & $9.2 \pm 0.7$ \\
\hline Plasma insulin (pmol/L) & $37.0 \pm 6.9$ & $36.8 \pm 3.0$ & $24.5 \pm 3.0$ & $26.5 \pm 4.8$ \\
\hline Liver lipids (mg total fatty acids/g tissue) & $30.3 \pm 2.9$ & $34.0 \pm 3.0$ & $30.3 \pm 0.6$ & $33.1 \pm 3.7$ \\
\hline \multicolumn{5}{|l|}{ Lipid peroxidation markers in plasma (nM) } \\
\hline 4-HHE & $23.3 \pm 13.5$ & $103.7 \pm 36.5$ & $88.8 \pm 32.0$ & $128.0 \pm 37.5$ \\
\hline 4-HNE & $4.9 \pm 0.3^{*}$ & $13.4 \pm 0.5$ & $5.9 \pm 1.1^{*}$ & $8.6 \pm 0.3^{*}$ \\
\hline
\end{tabular}

$\left({ }^{*} \mathrm{P}<0.05\right.$ vs HF); ( ${ }^{\$} \mathrm{P}<0.05$ vs LF), ANOVA followed by Fisher test.

Data are mean \pm SEM for $n=8$ per group. Abbreviations: WAT, white adipose tissue; TAG, plasma triacyglycerols; NEFA, non-esterified fatty acids; 4-HHE, 4-hydroxy -2-hexenal; 4-HNE, 4-hydroxy-2-nonenal.

For 4-hydroxy-2-alkenals analysis, 3 pools of $300 \mu \mathrm{L}$ obtained from 3 mice (100 $\mu \mathrm{L}$ per mice) were used for each group ( $n=3$ ). 
consumption of different diets could change PUFA metabolism. In fact, the profile of total FA in plasma (Table 4), in liver and eWAT (See Additional file 2) reflected the composition of ingested dietary fats (Table 2). FA profile of rWAT was similar to that of eWAT (See Additional file 3).

Table 4 shows that the plasma arachidonic acid (20:4 $n-6)$, an $n-6$ FA precursor of pro-inflammatory mediators in biological membranes, was significantly higher in HF group than in three other groups. EPA proportion was higher in plasma of mice fed the HF diets supplemented with $n-3$ PUFA compared with HF group, and higher in HF- $\omega 3 \mathrm{TG}$ group than in HF- $\omega 3 \mathrm{PL}$ group. Importantly, plasma DHA was higher in the two HF groups supplemented with LC $n-3$ PUFA in the form of PL or TG compared with LF and HF groups. Additionally, the proportions of LC $n$ - 3 PUFA (EPA and DHA) were higher in the HF- $\omega 3$ TG group than in the HF$\omega 3 \mathrm{PL}$ group as observed in the diets.

In liver like in eWAT, DHA and EPA levels were significantly increased in both HF- $\omega 3 \mathrm{PL}$ and HF- $\omega 3 \mathrm{TG}$ groups compared to LF and HF groups. A significant difference of LC $n$-3 PUFA levels was observed between

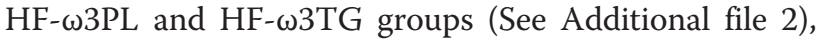
as observed in the plasma. The $n-6 / n-3$ ratio, related to a risk of inflammation derived from PUFA metabolites, was higher in mice fed HF diet than the three other groups. This ratio was not different between HF- $\omega 3 \mathrm{PL}$ and HF- $\omega 3$ TG groups (Table 4 and Additional file 2). The relative difference of $n-6 / n-3$ ratio that existed between the high-fat diets and the LF diet was altogether still observed in plasma and tissues after 8 weeks of diet
(Figure 1). Altogether, both diets enriched in LC $n-3$ PUFA resulted in proper accretion of these FA in tissues.

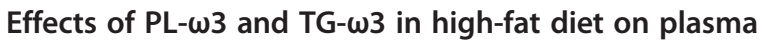
markers of inflammation, metabolic endotoxemia and oxidative stress

High-fat diets are known to induce a metabolic inflammation related to (i) the concentrations of different types of adipokines and (ii) endotoxin transport. Regarding inflammation, we show higher concentrations in plasma of the chemokine MCP-1 (Figure 2A) in HF group than in the three other groups. Plasma interleukin IL-6 was also significantly higher in HF group than in HF- $\omega 3 \mathrm{PL}$ group (Figure $2 \mathrm{~B}$ ) and tended to be higher in HF group than in HF- $\omega 3$ TG mice $(P=0.06)$. Both $n-3$ diets even resulted in plasma concentrations of inflammatory markers similar to the LF diet. Among plasma markers involved in the transport of the pro-inflammatory endotoxins, the lipopolysaccharide binding protein (LBP) level was higher in plasma of HF mice than in LF and HF- $\omega 3 \mathrm{PL}$ groups (Figure 2C). However, no difference was found

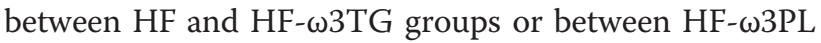

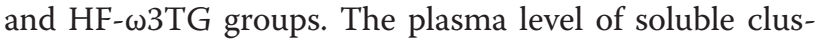
ter of differentiation 14 (sCD14), an endotoxin receptor, was also higher in HF mice than in the two HF groups supplemented with LC $n$-3 PUFA (Figure 2D). Regarding adipokines in plasma, results showed an increased leptin concentration in the HF group $v s$ all other groups (Figure 2E). Supplementation with LC $n-3$ PUFA in both forms allowed recovering leptin concentrations similar to LF group. In contrast, there was no difference in plasma adiponectin concentration among the groups (Figure 2F).

Table 4 Fatty acid profile in plasma in mice fed different diets

\begin{tabular}{|c|c|c|c|c|}
\hline Major FA in plasma & LF & $\mathrm{HF}$ & HF- $\omega 3$ PL & HF- $\omega 3$ TG \\
\hline \multicolumn{5}{|c|}{ Total FA (mol/100 mol FA): } \\
\hline SFA & $33.7 \pm 0.3$ & $34.5 \pm 0.2$ & $34.4 \pm 1.3$ & $36.1 \pm 2.6$ \\
\hline $16: 1 n-7$ & $4.0 \pm 0.5$ & $1.6 \pm 0.2^{\$}$ & $1.2 \pm 0.02^{\$}$ & $1.6 \pm 0.4^{\$}$ \\
\hline $18: 1 n-7$ & $2.7 \pm 0.2$ & $1.5 \pm 0.1^{\$}$ & $1.3 \pm 0.1^{\$}$ & $1.4 \pm 0.3^{\$}$ \\
\hline $18: 1 n-9$ & $19.3 \pm 1.9$ & $15.6 \pm 0.7^{\$}$ & $16.1 \pm 1.9^{\$}$ & $13.4 \pm 6.7^{\$}$ \\
\hline MUFA & $27.9 \pm 1.0$ & $19.6 \pm 0.3^{5}$ & $19.5 \pm 0.2^{\$}$ & $17.3 \pm 6.7^{\$}$ \\
\hline $18: 2 n-6$ & $21.2 \pm 0.6$ & $25.4 \pm 0.2^{\$}$ & $26.1 \pm 0.4^{\$}$ & $26.4 \pm 0.8^{\$}$ \\
\hline $20: 4 n-6$ & $9.6 \pm 1.2^{*}$ & $14.3 \pm 0.4$ & $11.2 \pm 0.5^{*}$ & $9.5 \pm 0.8^{*}$ \\
\hline$n-6$ & $33.1 \pm 0.9^{*}$ & $42.1 \pm 0.5$ & $39.2 \pm 1.0^{\$}$ & $38.2 \pm 3.2^{\xi^{*}}$ \\
\hline $18: 3 n-3$ & $0.4 \pm 0.1$ & $\operatorname{Tr}^{s}$ & $0.3 \pm 0.0^{*}$ & $0.2 \pm 0.0^{5 *}$ \\
\hline $20: 5 n-3$ & $0.7 \pm 0.0$ & $\operatorname{Tr}^{\$}$ & $0.7 \pm 0.0^{*}$ & $1.2 \pm 0.1^{\xi^{*}}$ \\
\hline $22: 6 n-3$ & $3.8 \pm 0.4$ & $3.2 \pm 0.1$ & $4.9 \pm 0.3^{\xi^{*}}$ & $6.6 \pm 0.5^{\xi^{*}}$ \\
\hline$n-3$ & $5.2 \pm 0.4$ & $3.9 \pm 0.1^{\$}$ & $6.4 \pm 0.2^{*_{\AA}}$ & $8.4 \pm 1.3^{3^{*}}$ \\
\hline$n-6 / n-3$ ratio & $6.4 \pm 0.3^{*}$ & $10.9 \pm 0.4$ & $6.1 \pm 0.2^{*}$ & $4.6 \pm 0.4^{*}$ \\
\hline
\end{tabular}

( ${ }^{*} \mathrm{P}<0.05$ vs HF), ( ${ }^{5} \mathrm{P}<0.05$ vs LF), $\left({ }^{\mathrm{f}} \mathrm{P}<0.05\right.$ vs HF- $\left.\omega 3 \mathrm{TT}\right)$. Data are mean \pm SEM for $\mathrm{n}=5$ per group. Abbreviations: Tr, traces FA; fatty acids; MUFA, monounsaturated fatty acids; SFA, saturated fatty acids. 


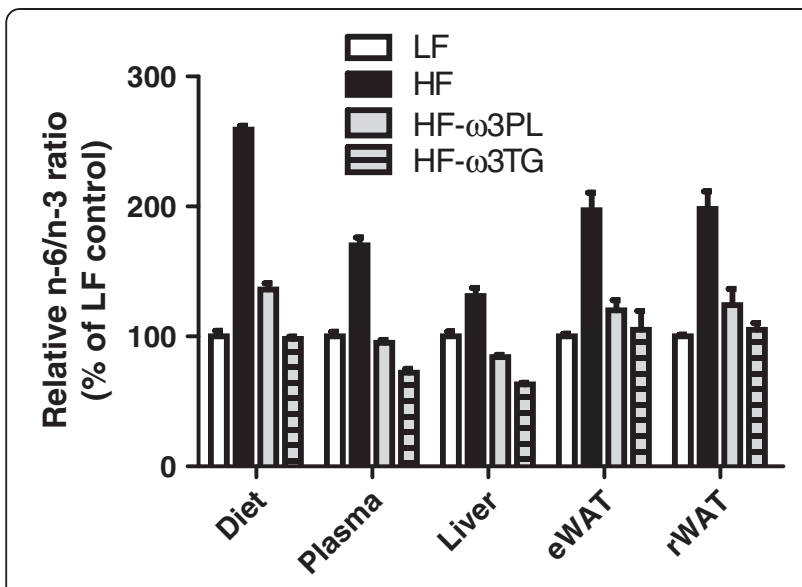

Figure 1 Relative $n-6 / n-3$ fatty acid ratio in diets, plasma, Liver and WAT. The mice were fed LF, HF, HF- $\omega 3 \mathrm{PPL}$ and HF- $\omega 3 \mathrm{TG}$ diets. The values were expressed as percentage of the ratio measured in the groups. Data are means \pm SEM $(n=3-6)$.

LC PUFA are known to be prone to oxidation because of their high degree of unsaturation. They form oxidized end-products which contribute to oxidative stress. We measured the levels of 4-hydroxy-2-hexenal (4-HHE) and 4-hydroxy-2-nonenal (4-HNE), two markers of lipid peroxidation derived from the oxidation of $n$ - 3 PUFA and $n-6$ PUFA respectively. As shown in Table 3 , the plasma level of 4-HHE did not differ among the groups, although there was large variation within groups. The plasma level of 4-HNE was significantly higher in HF group than in the three other groups albeit remaining low (Table 3). No differences in 4-HHE and 4-HNE concentrations were observed in the liver that is a major target organ for these alkenals $(0.5$ to $2 \mathrm{nmol} / \mathrm{g}$ regardless of group).

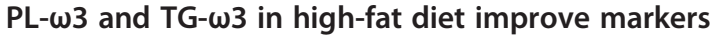
related to inflammation and oxidative stress in WAT Because we noticed a significant decrease of inflammatory markers in the plasma of mice fed HF diet supplemented with LC $n$-3 PUFA, we examined the MCP-1 and IL-6 gene expression in WAT. MCP-1 expression in eWAT was significantly higher in HF group than in the other groups (Figure $3 \mathrm{~A}, P<0.01$ ). The same difference between $\mathrm{HF}$ and HF- $\omega 3 \mathrm{PL}$ groups was observed in rWAT (see Additional file 4). The expression of mRNA IL-6 was significantly decreased in HF$\omega 3$ TG group compared to HF group and tended to be decreased in HF- $\omega 3 \mathrm{PL}$ group compared to HF group (Figure 3B). In addition, the level of tocopherols was

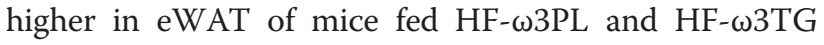
diets than LF and HF groups (Figure 3C). Noticeably, the level of tocopherols was higher in HF- $\omega 3 \mathrm{PL}$ group than in HF- $\omega 3$ TG group $(\mathrm{P}<0.05)$ despite the similar levels found in the diets (Table 2). The concentration of the oxidation products 4-HHE and 4-HNE in eWAT and rWAT was similar among groups, in the range 0.5 to $2 \mathrm{nmol}$ per $\mathrm{g}$.

\section{PL- $\omega 3$ and TG- $\omega 3$ in high-fat diet affect adipocyte size distribution in WAT differently}

To know whether the high-fat diets could affect the size and the number of adipocytes in mice, we performed a cellularity analysis of WAT. As shown Figure 4, the size distribution of the epididymal adipocytes in the HF$\omega 3 \mathrm{PL}$ group showed a marked shift toward smaller sizes compared with HF and HF- $\omega 3$ TG groups. The same effect was observed in retroperitoneal fat pads. The cellular characteristics of eWAT in mice fed HF and HF supplemented with LC $n-3$ PUFA in the form of PL or TG are shown in Table 5. A reduction of fat accretion in eWAT was observed in HF- $\omega 3 \mathrm{PL}$ group vs HF group but no difference was observed between HF- $\omega 3$ TG and the two other groups. Adipocyte sizes in HF- $\omega 3 \mathrm{PL}$ and LF groups were actually similar. This reduction resulted from a decrease in adipose cell volume rather than from a decrease in the total number of adipocytes per fat pad, as calculated from the measured size distribution. Indeed, mean adipocyte diameter was reduced by $14 \%$ in HF- $\omega 3 \mathrm{PL}$ group $v s \mathrm{HF}$ group $(P<0.05)$ resulting in a $30 \%$ decrease in calculated adipose cell volume $(P=0.03)$.

\section{Effect of PL- $\omega 3$ and TG- $\omega 3$ in high-fat diet on oxidative stress in the small intestine}

The upper small intestine represents the primary defense line of the organism that can affect metabolism and inflammation. We thus examined the gene expression of gastrointestinal glutathione peroxidase 2 (GPx2), mainly expressed in the small intestine and implicated in the detoxification of lipid oxidation products including 4-HHE and 4-HNE. The expression of GPx2 in the duodenum was higher in HF mice than in LF and HF- $\omega 3 \mathrm{PL}$ groups (Figure 5A). In the jejunum, the gene expression of GPx2 was significantly increased in HF group compared with the three other groups (Figure 5B).

\section{Discussion}

In the present study, we investigated (i) the effects of long-term consumption of HF diet supplemented with LC $n$-3 PUFA in the form of PL or TG on adiposity, oxidative stress and inflammation and (ii) whether the PL or TG carrier can affect these parameters. For this purpose, we designed a HF diet containing $20 \%$ of fat, rich in saturated fatty acids and with a relatively high $n-6 / n-3$ ratio to mimic the lipid-enriched foods as consumed in typical Western diets. Importantly, all diets contained the same amount of PL, in the form of PL-DHA in HF$\omega 3 \mathrm{PL}$ diet and in the form of lecithin PL-LA in all other 


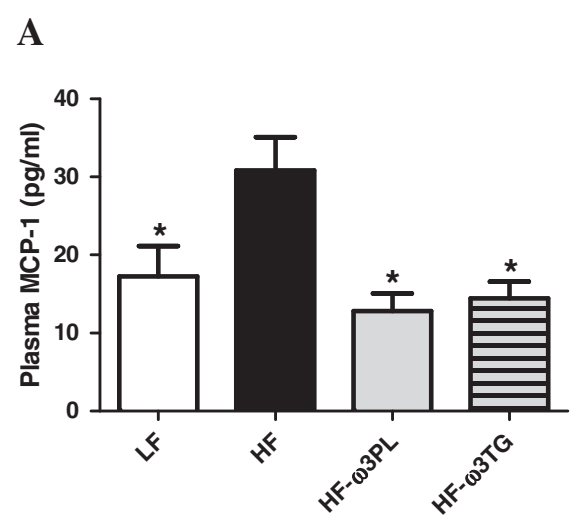

C

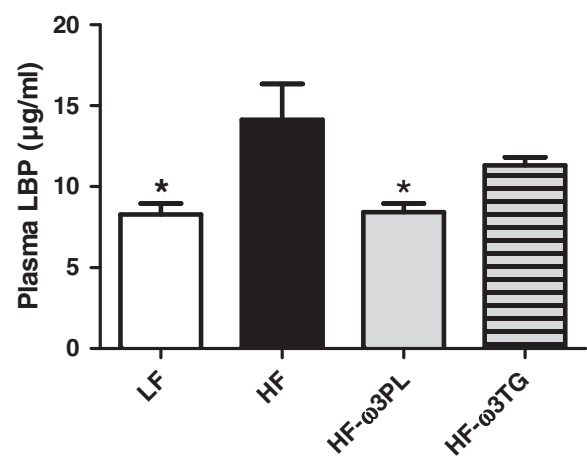

E

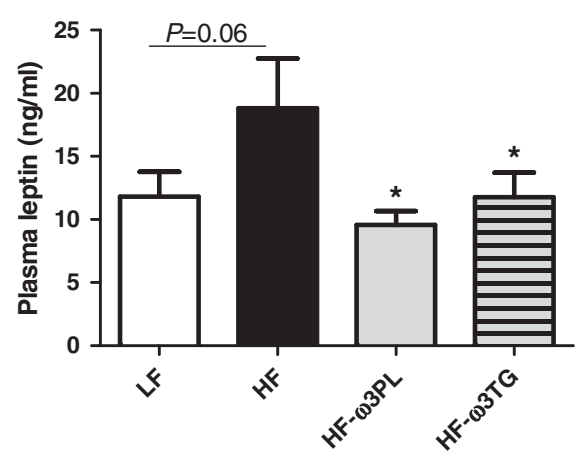

B

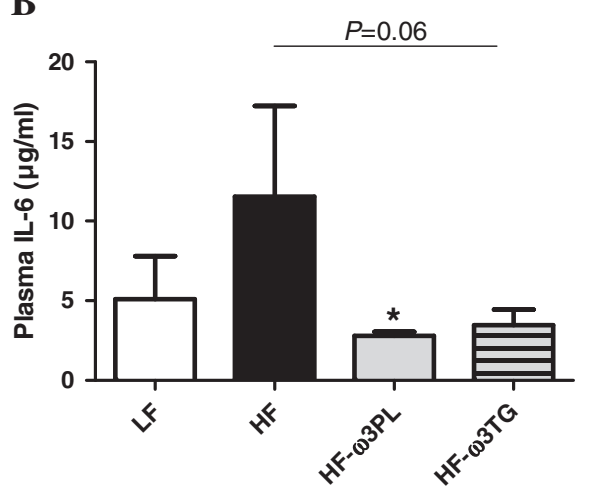

D

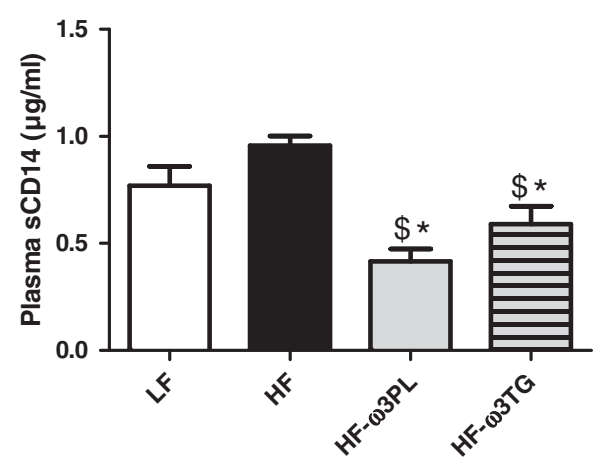

F

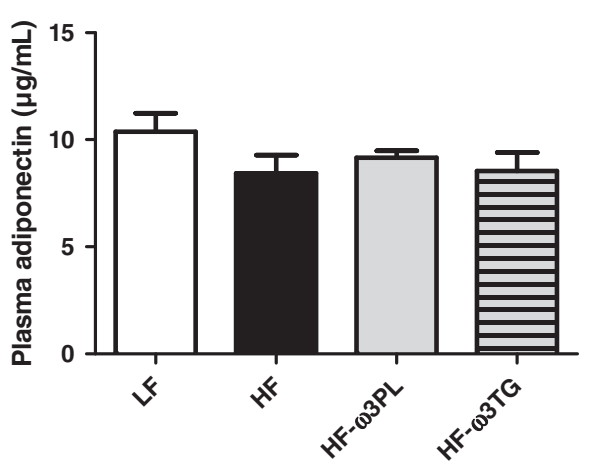

Figure 2 Inflammation and endotoxin metabolism parameters in plasma of mice fed different diets. (A) monocyte chemoattractant protein-1 (MCP-1; pg/ml); (B) Interleukin-6 (IL-6; $\mu \mathrm{g} / \mathrm{ml})$. (C) lipopolysaccharide binding protein (LBP; $\mu \mathrm{g} / \mathrm{ml})$. (D) (soluble cluster of differentiation $14(\mathrm{sCD} 14 ; \mu \mathrm{g} / \mathrm{ml})$. (E) leptin $(\mathrm{ng} / \mathrm{ml}) ;(\mathbf{F})$ Adiponectin $(\mu \mathrm{g} / \mathrm{ml})$. Data are means $\pm \mathrm{SEM}(\mathrm{n}=6-8) .{ }^{*} \mathrm{P}<0.05$ vs HF); $\left({ }^{\$} \mathrm{P}<0.05\right.$ vs LF). ANOVA followed by Fisher test.

groups. This formulation ensured that the possible observed effects of PL- $\omega 3$ can be attributed to the location of $n$-3 PUFA in the diet (on PL rather than TG) and not to the presence of polar lipids that would have biased the interpretation.

We show that altogether, long-term intake of HF diet supplemented with LC $n$-3 PUFA protects against inflammation and oxidative stress induced by HF diets. This is in agreement with numerous studies documenting the beneficial health effects of LC $n-3$ PUFA $[19,37]$. In this study, the supplementation of HF diet with LC $n-3$ PUFA in the PL carrier was slightly lower than that in the TG carrier. Therefore, our results indicate that the effects of LC $n-3$ PUFA from lecithin rich in PL-DHA is more efficient than LC $n$-3 PUFA from tuna oil (mainly TGDHA). This supports the results of a previous study reporting that in healthy humans the metabolic effects of krill oil (mainly PL) are similar to those of fish oil but at lower dose of LC $n$-3 PUFA [27]. Importantly in previous studies, the PL carrier was provided by the bulk marine 


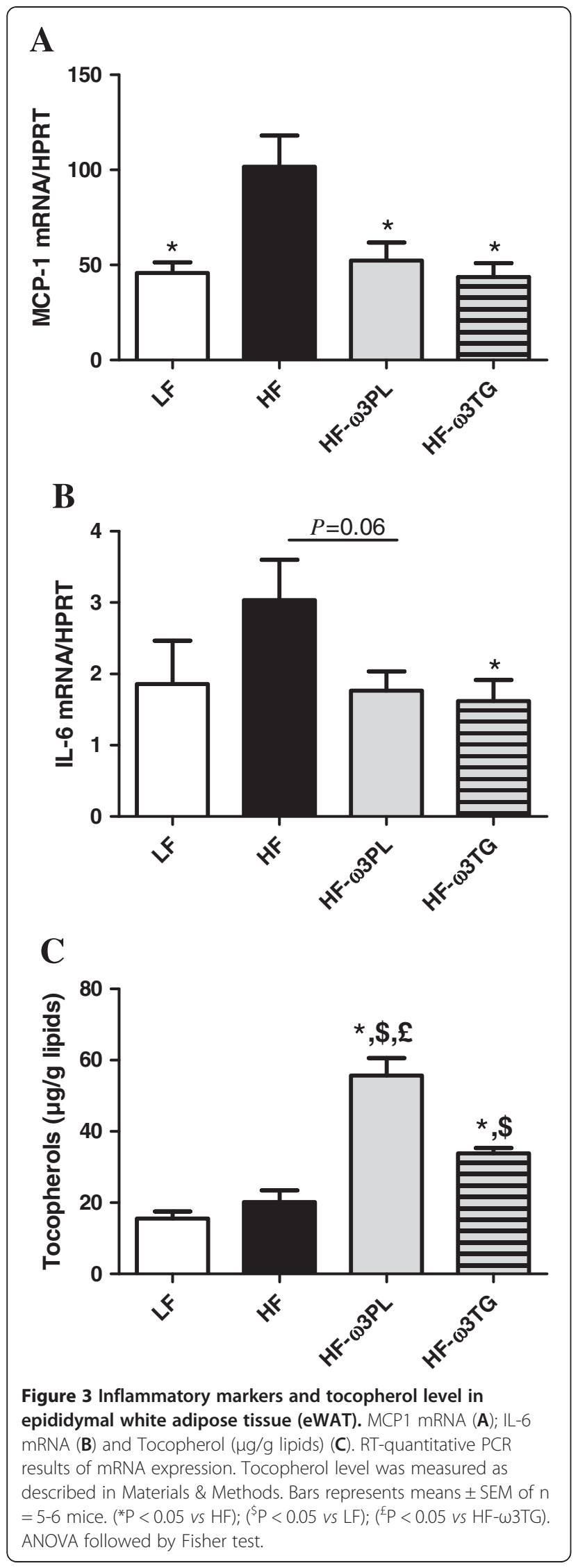

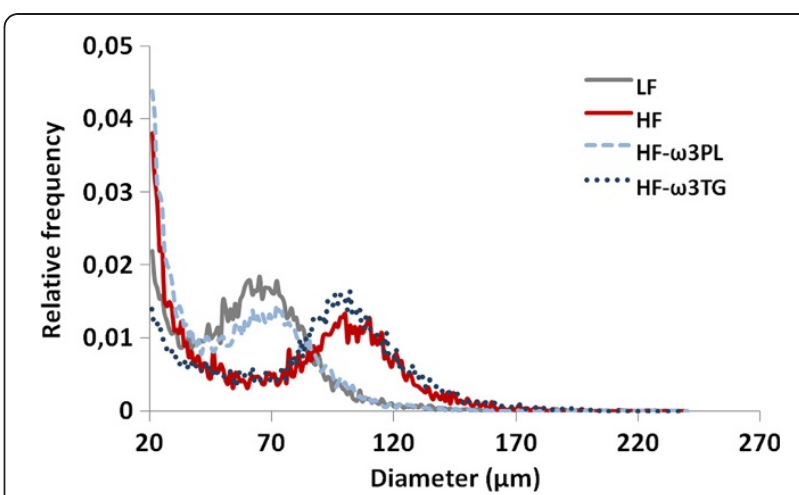

Figure 4 Frequency evolution of adipocyte size of mice in epididymal fat pad. Individual measurements were performed on 12 000-14 000 adipocytes using osmium tetroxide - coulter counter procedure as described in Methods. Note that distribution of adipocyte size was shifted leftward (ie. Towards smaller size) in HFW3PL mice compared to HF and HF-w3TG mice. Value are shown for one representative curve for each group.

sources, i.e. krill oil [25-28]. Usually, the percentage of PL in these products is $40 \%$, which means that a part of $n-3$ PUFA brought by the krill oil was in fact bound to TG carrier in these studies.

In the present study, a dietary intake of LC $n$-3 PUFA during 8 weeks resulted in an increased incorporation of DHA into plasma, liver and WAT lipids, the FA composition of the organs reflecting the fatty acid profiles of the diets. Regardless of the LC $n-3$ PUFA carrier, the $n-6 / n-3$ ratio in plasma, liver and WAT of mice fed HF$\omega 3 \mathrm{PL}$ and HF- $\omega 3 \mathrm{TG}$ was lower than in the HF diet. The ratio was almost similar in both HF- $\omega 3 \mathrm{PL}$ and HF$\omega 3$ TG groups, while the HF- $\omega 3$ TG group showed a significantly higher proportion of DHA than the HF- $\omega 3 \mathrm{PL}$ group. A decreased $n-6 / n-3$ ratio in tissues has been reported to reduce atherosclerosis due to the inhibition of systemic and vascular inflammation in apolipoprotein E-deficient mice. The authors attributed these protective effects to the anti-inflammatory properties of $n-3$ PUFA [38]. In addition, the proportion of EPA in WAT was higher in mice fed the HF diets supplemented with LC $n$-3 PUFA compared with HF, suggesting that the turnover of DHA in eWAT is high. The increase in EPA concentration paralleled the increased level of DHA in HF- $\omega 3$ TG more than in HF- $\omega 3$ PL.

LC n-3 PUFA are known to reduce metabolic inflammation in human and rodents [39-41]. Our data show that the HF diet induced higher IL-6, MCP-1 levels in plasma and in eWAT than LF diet. Interestingly, no activation of these pro-inflammatory markers was observed in HF- $\omega 3 \mathrm{PL}$ and in HF- $\omega 3$ TG groups, even if the EPA + DHA dose in the HF- $\omega 3$ PL is lower of that in the HF$\omega 3$ TG group. This may indicate that LC $n-3$ PUFA derived from PL provide a better bioavailability and/or bioactivity than those esterified into TG. Our results 
Table 5 Comparison of adipose cell size variables in eWAT of LF, HF, HF-w3PL and HF-w3TG mice

\begin{tabular}{lcccc}
\hline & LF & HF & HF- $\boldsymbol{\omega} 3 \mathbf{P L}$ & HF- $\boldsymbol{\omega} 3 \mathbf{T G}$ \\
\hline eWAT & & & & \\
\hline eWAT $(\mathrm{mg})$ & $502 \pm 29$ & $588 \pm 69$ & $423 \pm 21^{*}$ & $536 \pm 59$ \\
Mode $(\mu \mathrm{m})$ & $77.3 \pm 3.9^{*}$ & $89.3 \pm 6.0$ & $75.6 \pm 1.8^{*}$ & $84.9 \pm 5.5$ \\
Cell diameter $(\mu \mathrm{m})$ & $67.1 \pm 3.1^{\#}$ & $74.6 \pm 3.4$ & $64.3 \pm 3.0^{*}$ & $70.5 \pm 4.1$ \\
Cell weight $(\mathrm{ng})$ & $455.5 \pm 46.5^{\#}$ & $619.9 \pm 49.2$ & $434.8 \pm 42.9^{*}$ & \\
Nb cells $\left(\times 10^{6}\right)$ & $1.19 \pm 0.01$ & $1.12 \pm 0.14$ & $1.03 \pm 0.07$ & \\
\hline
\end{tabular}

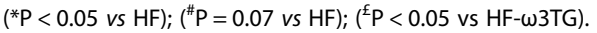

Data are mean \pm SEM for $n=4-5$ per group. Abbreviations: eWAT, epididymal white adipose tissue.

suggest that LC $n$-3 PUFA, regardless of their molecular form, could inhibit the low-grade inflammation by directly inhibiting macrophage immigration through the inhibition of MCP-1.

Our data are consistent with previous studies reporting that the inflammatory response in WAT induced by $\mathrm{HF}$ diet in obese diabetic animals was prevented by the supplementation HF with $n-3$ PUFA either in the form of PL or TG $[6,21]$. Batetta et al. concluded that such anti-inflammatory effects can be due to observed lower levels of arachidonic acid in membrane phospholipids [24].

Recent studies revealed the complementary role of metabolic endoxotemia in the low-grade inflammation. Laugerette et al. observed that endotoxin transporter LBP was positively correlated with plasma IL-6 in mice fed a palm oil-based high-fat diet, which was reversed using rapeseed oil [42]. Other works evidenced a link between low-grade inflammation or related metabolic disorders and plasma LBP and sCD14 [43,44]. In our study, the HF group presented the highest plasma concentration of LBP, consistently with inflammatory markers. A significant decrease in the level of plasma sCD14 was observed in HF- $\omega 3$ PL and HF- $\omega 3$ TG groups. Altogether, our results indicate that the supplementation of HF diet with LC $n$-3 PUFA can lower plasma concentrations of endotoxin transporters. Further mechanisms should be investigated to elucidate the implication of $n-3$ PUFA sources in the regulation of endotoxemia-induced metabolic inflammation.

Circulating leptin levels are directly associated with the mass of WAT and inflammation [45]. Our results showed that the plasma levels of leptin, mainly produced by adipocytes, were decreased in the two supplemented groups with LC $n-3$ PUFA in the form of PL or TG vs HF mice. Plasma leptin was also lower in HF-w3TG group independently of WAT mass, suggesting a relationship between the lower metabolic inflammation and the leptin. Our results are in agreement with a previous study showing that long-term intake of dietary $n-3$ PUFA by rats resulted in a significant decrease in plasma leptin levels [46].

Adiponectin plays an important role as insulinsensitizing adipokine which production is decreased in obesity and in conditions associated with insulin resistance $[5,47]$. In our study, we did not observed a significant difference in circulating adiponectin level among groups. In addition, the glucose and insulin tolerances were not affected by the different diets. Our results are in agreement with previous study reporting that the level
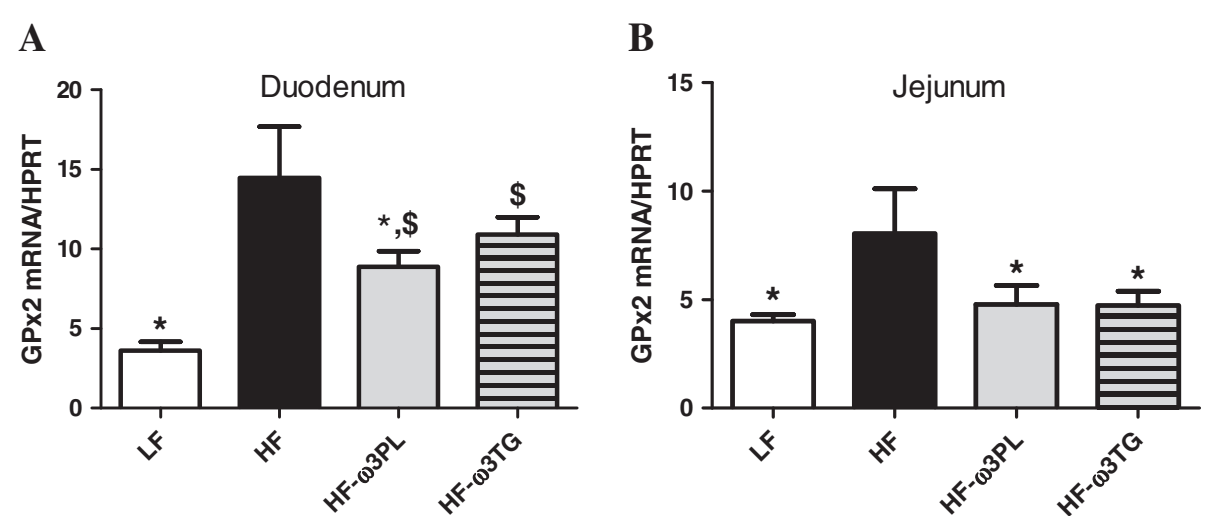

Figure 5 Expression of gastro-intestinal glutathione peroxidase 2 (GPx2) RNA in the small intestine. (A) duodenum and (B) jejunum of mice fed LF, HF, HF-w3PL and HF-w3TG diets during 8 weeks. This analysis was quantified by qPCR. Bars represents means \pm SEM of $n=5-6$ mice. ( ${ }^{*} \mathrm{P}<0.05$ vs HF); ANOVA followed by Fisher test. 
of adiponectin was not different between HF group (35\% of fat) and DHA/EPA in the form of PL or TG supplemented to the HF diets for 8 weeks [21]. Conversely, other studies showed a decrease in the level of plasma adiponectin after feeding mice a HF diet; this level was restored by the supplementation HF diet with DHA and EPA [6,29]. Altogether, such modifications in plasma adiponectin concentrations are reported with different lipid types ( $n-6$ PUFA-rich corn oil instead of lard) and/or concentrations in the diet $(35 \% \mathrm{w} / \mathrm{w}$ instead of $20 \%$ ) and using larger doses of fish oil (15-40\% in total dietary lipids) compared with the present study (5\%).

Regarding adiposity, HF diet did not induce significantly higher body weight gain than the low fat control, although a trend towards heavier adipose tissue was observed. This can be due to our choice of preparing LF and HF groups using similar ingredients. Both LF and HF were semi-synthetic and based mainly on corn starch and casein, while many studies in the literature reach weight gain by comparing semi-synthetic high-fat diet with regular chow based on more various ingredients [48]. Among the HF diets, HF- $\omega 3$ PL diet led to a lower weight gain and a reduced adipose tissue compared with HF group without affecting the mass of muscles. However these effects were not observed in mice fed HF$\omega 3$ TG. These results suggest that the PL carrier can decrease body fat deposition more than the TG carrier. This is consistent with a previous study reporting that obese mice fed LC $n$-3 PUFA carried by PL developed less body weight gain than those fed LC $n-3$ PUFA carried by TG [21]. We further investigated the effect of HF diet containing LC $n$-3 PUFA in the form of PL or TG on the cell size distribution of adipose tissue by using the Coulter counter method (Multisizer IV, Beckman Coulter) which allows a more precise cell-size distribution because the number of cell counted is much higher than the one of microscopic methods. The most noticeable difference between groups was in the adipocyte size distribution. Mice fed HF diet showed an increased adipocyte size compared with those fed the LF diet. Differential effects were observed regarding LC $n-3$ PUFA supplementation; HF- $\omega 3$ PL and LF diets induced similar adipocyte size whereas HF- $\omega 3$ TG and HF diets led to larger adipocytes. Our results following a $20 \%$ w/ w high-fat diet for 8 weeks are consistent with those of Rossmeisl et al. [21]. These authors observed that the PL carrier decreased adipocyte area compared with the control HF diet in obese mice, which was not observed using the TG carrier. Of note, endothelial lipase presents specificity towards DHA-containing PL, thus generating Lyso-PL containing DHA [49]. Moreover, our PL source also contained Lyso-PC-DHA. We may hypothesize that such DHA-containing lipid species might exert specific biological activity, because superior biological effects of LysoPC-DHA have otherwise been demonstrated regarding DHA accretion in the brain and anti-inflammatory activity [50,51]. However, further research is required to better understand the mechanism of action of PL carrier.

Skurk et al. investigated the secretory capacity of adipocyte fractions from the same individual. They demonstrated that the large adipocytes were implicated in the induction of pro-inflammatory genes such as those coding for IL-6 and MCP-1 [52]. Consistently, HF diet-induced-inflammation can be associated with large adipocytes. Regarding the impact of supplementing with $n-3$ PUFA, noticeably, the HF- $\omega 3$ PL diet had a greater anti-adiposity effect than the HF- $\omega 3 \mathrm{TG}$ diet associated with smaller adipocytes. Here, the anti-adiposity effect of HF- $\omega 3$ PL diet could be partly associated with the lower metabolic inflammation in the mice. In contrast, the anti-inflammatory effect of HF- $\omega 3 \mathrm{TG}$ was not associated with a decrease in adiposity.

We further investigated the effect of the composition of the dietary high-fat, and more specifically of the presence of LC $n$-3 PUFA on lipid peroxidation and oxidative stress. LC PUFA are molecules susceptible to oxidation because they contain many double bonds. PUFA oxidation leads to the formation of secondary end-products such as 4-HNE derived from $n-6$ PUFA and 4-HHE derived from $n$-3 PUFA [53]. Our previous studies in mice showed that these markers can induce oxidative stress and inflammation, even when consumed in moderately oxidized dietary fat [30]. They also provoke oxidative stress in vitro in Caco-2 cells [30]. In the present study, similar levels of plasma 4-HHE were measured in the three HF mice groups; however the plasma level of 4-HNE was increased in HF mice compared with the other groups. Previously, Esterbauer et al. found that the basal concentrations of 4-HNE in the human serum were in the range $0-700 \mathrm{nM}$. In our study, plasma 4-HNE in mice remained within this range observed in humans [54]. In liver and in WAT, the levels of 4-hydroxy-2-alkenals were lower than $2 \mathrm{nmol} / \mathrm{g}$, which is in the same order of magnitude than in another study reporting basal concentrations of 4-HNE in the liver of mice [55]. We thus suggest that the dietary highfat used in this study may slightly enhance the oxidative stress through the induction of 4-HNE in plasma, albeit without increase of 4-HNE in tissues. LC $n-3$ PUFA supplementation prevented this phenomenon.

We propose that the increase of oxidative stress after HF diet consumption is linked to an alteration of antioxidant defenses. In the gastro-intestinal tract, a defense system including GPx2, is able to detoxify lipid peroxidation products and protect against inflammation $[30,56,57]$. Our results show a significant increase of GPx2 mRNA in the duodenum of mice fed HF vs HF- 
$\omega 3 \mathrm{PL}$ diets. Interestingly, a significant difference of GPx2 mRNA in the jejunum was also observed between HF vs HF- $\omega 3$ PL mice. Meanwhile, we observed a significant difference between HF $v s$ HF- $\omega 3$ TG groups in the jejunum. This suggests that (i) the HF diet-induced-inflammation could alter the anti-oxidant defense system in the intestine and (ii) the supplementation of HF diet with LC $n-3$ PUFA in the form of PL is more bioactive in the upper intestine than those in the form of TG.

Regarding the concentration of $\alpha$-tocopherol, a lipidsoluble antioxidant vitamin, we show that it was significantly increased in the WAT of HF- $\omega 3 \mathrm{PL}$ and HF- $\omega 3 \mathrm{TG}$ groups as compared to HF mice. Interestingly, tocopherol level in WAT was significantly greater in HF- $\omega 3 \mathrm{PL}$ than in HF- $\omega 3$ TG mice. Of note, in this study we took care to adjust dietary tocopherol to obtain similar concentrations in our diets. Thus, our results can be attributed to the direct effects of PL-bound vs TGbound LC $n-3$ PUFA. Consistently, Choi et al. recently reported that high-fat diet enhanced the oxidative stress through the decreased level of tocopherols in the livers of rats [58]. Thus, our findings suggest that dietary supplementation with LC $n$-3 PUFA is beneficial for decreasing lipid peroxidation in high fat-fed mice, and that the PL carrier may induce a superior bioavailability to tocopherols or lower need for their use to counteract oxidative stress. The enhanced level of $\alpha$ - tocopherol following LC $n$-3 PUFA in the form of PL can also be an effective defense against oxidative stress and inflammation. Further studies should analyze the amount and distribution of vitamin $\mathrm{E}$ among different tissues after the diets. The effect of dietary $n-3$ PUFA in the form of PL and TG on the activity of anti-oxidant systems should also be clarified by further studies in humans. Altogether, HF diet induced concomitant increase in plasma 4-HNE, GPx-2 activation in the small intestine and lower tocopherol level in WAT; all of these markers being reversed by the supplementation with $\mathrm{LC} n-3$ PUFA.

\section{Conclusion}

In conclusion, our study demonstrates in mice that long-term ingestion of $n-3$ PUFA prevents HF dietinduced inflammation and oxidative stress. Compared with triacylglycerols, LC $n-3$ PUFA supplemented in the form of PL exhibit superior beneficial metabolic effects by decreasing adiposity, reducing adipocyte size and stimulating the anti-oxidant system. Our findings should be strengthened by dietary intervention studies in human aimed at testing the impact of different LC $n-3$ PUFA molecular forms on the structure and metabolism of adipose tissue. Such findings could support the development of functional foods containing LC $n-3$ PUFA in the form of PL participating to the prevention of the development of chronic metabolic diseases in humans like obesity.

\section{Additional files}

Additional file 1: Fatty acid composition in tuna oil and in purified PL-DHA.

Additional file 2: Fatty acid profile in liver and eWAT of mice fed different diets.

Additional file 3: Fatty acid profile in rWAT in mice fed different diets.

Additional file 4: MCP1 mRNA level in retroperitoneal white adipose tissue (rWAT).

\section{Abbreviations}

PUFA: Polyunsaturated fatty acids; LF: Low fat; HF: High-fat;

DHA: Docosahexaenoic acid; EPA: Eicosapentaenoic acid; TG: Triacylglycerols; PL: Phospholipids; WAT: White adipose tissue; 4-HHE: 4-hydroxy-2-hexenal; 4HNE: 4-hydroxy-2-nonenal; GPx2: Gastrointestinal glutathione peroxidase 2; IL: Interleukin; MCP-1: Monocyte chemotactic protein-1;

LBP: Lipopolysaccharide binding protein; SCD14: Soluble cluster of differentiation.

\section{Competing interests}

The authors have no competing interests to disclose.

\section{Authors' contribution}

MA designed research, performed experiments, interpreted data and wrote the manuscript. COS, AM, LH, AG, MV and CD performed experiments, interpreted data and helped edit the manuscript. BB and LR performed experiments. ML and MG contributed to manuscript preparation. CG supervised the project and helped edit the manuscript. MCM supervised the work, designed research, interpreted data and wrote the manuscript. All authors read and approved the final manuscript.

\section{Acknowledgements}

This work was supported by the French National Research Agency (ANR): ANR-08-ALIA-002, AGECANINOX project. M. Awada acknowledges PhD grant from ANR. We thank J.M. Chardigny for useful discussions. N. Bernoud-Hubac is acknowledged for discussions on n-3 PUFA metabolism. We thank H. Soula for computing adipocyte size distribution analysis. N. Guillot is

acknowledged for editing English language.

\section{Author details}

${ }^{1}$ INRA, U1362, CarMeN, VilleurbanneF-69621France. ${ }^{2}$ INSA-Lyon, IMBL, Villeurbanne F-69621, France. ${ }^{3}$ INRA, UR1268 BIA, Nantes F-44316, France. ${ }^{4}$ INSERM U1060, CarMeN, Oullins F-69921, France. ${ }^{5}$ Université de Lyon, Villeurbanne F-69622, France. ${ }^{6}$ INRA USC1362, INSERM U1060, Cardiovasculaire Métabolisme diabétologie et Nutrition, CarMeN Laboratory, InFoLip team, IMBL Building, INSA-Lyon, 11 avenue Jean Capelle, Villeurbanne cedex 69621, France.

Received: 20 September 2012 Accepted: 3 January 2013

Published: 15 February 2013

\section{References}

1. Hotamisligil GS: Inflammation and metabolic disorders. Nature 2006, 444:860-867.

2. Manabe I: Chronic inflammation links cardiovascular, metabolic and renal diseases. Circ J 2011, 75:2739-2748.

3. Zulet MA, Puchau B, Navarro C, Marti A, Martinez JA: Inflammatory biomarkers: the link between obesity and associated pathologies. Nutr Hosp 2007, 22:511-527.

4. Waki H, Tontonoz P: Endocrine functions of adipose tissue. Annu Rev Pathol 2007, 2:31-56

5. Ouchi N, Parker JL, Lugus JJ, Walsh K: Adipokines in inflammation and metabolic disease. Nat Rev Immunol 2011, 11:85-97. 
6. Todoric J, Loffler M, Huber J, Bilban M, Reimers M, Kadl A, Zeyda M, Waldhausl W, Stulnig TM: Adipose tissue inflammation induced by highfat diet in obese diabetic mice is prevented by $n-3$ polyunsaturated fatty acids. Diabetologia 2006, 49:2109-2119.

7. Weisberg SP, McCann D, Desai M, Rosenbaum M, Leibel RL, Ferrante AW Jr: Obesity is associated with macrophage accumulation in adipose tissue. J Clin Invest 2003, 112:1796-1808.

8. Xu H, Barnes GT, Yang Q, Tan G, Yang D, Chou CJ, Sole J, Nichols A, Ross JS, Tartaglia LA, Chen H: Chronic inflammation in fat plays a crucial role in the development of obesity-related insulin resistance. J Clin Invest 2003, 112:1821-1830.

9. Park S, Park NY, Valacchi G, Lim Y: Calorie restriction with a high-fat diet effectively attenuated inflammatory response and oxidative stressrelated markers in obese tissues of the high diet fed rats. Mediators Inflamm 2012, 2012.

10. Lankinen M, Schwab U, Erkkila A, Seppanen-Laakso T, Hannila ML, Mussalo H, Lehto S, Uusitupa M, Gylling H, Oresic M: Fatty fish intake decreases lipids related to inflammation and insulin signaling-a lipidomics approach. PLoS One 2009, 4:e5258 10.1371/journal.pone.0005258?.

11. Kopecky J, Rossmeisl M, Flachs P, Kuda O, Brauner P, Jilkova Z, Stankova B, Trrzicka E, Bryhn M: n-3 PUFA: bioavailability and modulation of adipose tissue function. Proc Nutr Soc 2009, 68:361-369.

12. Flachs $P$, Rossmeisl M, Bryhn M, Kopecky J: Cellular and molecular effects of $n-3$ polyunsaturated fatty acids on adipose tissue biology and metabolism. Clin Sci (Lond) 2009, 116:1-16.

13. Defilippis AP, Blaha MJ, Jacobson TA: Omega-3 Fatty acids for cardiovascular disease prevention. Curr Treat Options Cardiovasc Med 2010, 12:365-380

14. Leaf A: Cardiovascular effects of fish oils. Beyond the platelet Circulation 1990, 82:624-628.

15. Hashimoto M, Hossain S: Neuroprotective and ameliorative actions of polyunsaturated fatty acids against neuronal diseases: beneficial effect of docosahexaenoic acid on cognitive decline in Alzheimer's disease. J Pharmacol Sci 2011, 116:150-162.

16. Bousquet M, Calon F, Cicchetti F: Impact of omega-3 fatty acids in Parkinson's disease. Ageing Res Rev 2011, 10:453-463.

17. EFSA: Scientific Opinion on Dietary Reference Values for fats, including saturated fatty acids, polyunsaturated fatty acids, monounsaturated fatty acids, trans fatty acids, and cholesterol. EFSA Journal 2010, 8:1461. doi:10.2903/j.efsa.2010.1461

18. Tou JC, Jaczynski J, Chen YC: Krill for human consumption: nutritional value and potential health benefits. Nutr Rev 2007, 65:63-77.

19. Calder PC: The role of marine omega-3 (n-3) fatty acids in inflammatory processes, atherosclerosis and plaque stability. Mol Nutr Food Res 2012, 56:1073-1080

20. Morizawa KTY, Tsuchida M, Nakano Y, Hibino H, Tanaka Y: Dietary oils and phospholipids containing $n-3$ highly unsaturated fatty acids suppress 2,4-dinitro-1- fluorobenzene-induced contact dermatitis in mice. J Jpn Oil Chem Soc 2000, 49:59-65.

21. Rossmeisl M, Jilkova ZM, Kuda O, Jelenik T, Medrikova D, Stankova B, Kristinsson B, Haraldsson GG, Svensen $H$, Stoknes I, Sjovall P, Magnusson $Y$, Balvers MG, Verhoeckx KC, Tvrzicka E, Bryhn M, Kopecky J: Metabolic effects of n-3 PUFA as phospholipids are superior to triglycerides in mice fed a highfat diet: possible role of endocannabinoids. PLoS One 2012, 7:e38834. 10.1371/journal.pone.0038834

22. Hiratsuka S, Ishihara K, Kitagawa T, Wada S, Yokogoshi H: Effect of dietary docosahexaenoic acid connecting phospholipids on the lipid peroxidation of the brain in mice. J Nutr Sci Vitaminol (Tokyo) 2008, 54:501-506

23. Hiratsuka S, Koizumi K, Ooba T, Yokogoshi H: Effects of dietary docosahexaenoic acid connecting phospholipids on the learning ability and fatty acid composition of the brain. J Nutr Sci Vitaminol (Tokyo) 2009, 55:374-380

24. Batetta B, Griinari M, Carta G, Murru E, Ligresti A, Cordeddu L, Giordano E, Sanna F, Bisogno T, Uda S, Collu M, Bruheim I, Di Marzo V, Banni S: Endocannabinoids may mediate the ability of $(n-3)$ fatty acids to reduce ectopic fat and inflammatory mediators in obese Zucker rats. J Nutr 2009, 139:1495-1501.

25. Bunea R, El Farrah K, Deutsch L: Evaluation of the effects of Neptune Krill Oil on the clinical course of hyperlipidemia. Altern Med Rev 2004, 9:420-428.
26. Vigerust NF, Bjorndal B, Bohov P, Brattelid T, Svardal A, Berge RK: Krill oil versus fish oil in modulation of inflammation and lipid metabolism in mice transgenic for TNF-alpha. Eur J Nutr, . doi:10.1007/s00394-012-0441-2. in press.

27. Ulven SM, Kirkhus B, Lamglait A, Basu S, Elind E, Haider T, Berge K, Vik H, Pedersen Jl: Metabolic effects of krill oil are essentially similar to those of fish oil but at lower dose of EPA and DHA, in healthy volunteers. Lipids 2011, 46:37-46.

28. Maki KC, Reeves MS, Farmer M, Griinari M, Berge K, Vik H, Hubacher R, Rains TM: Krill oil supplementation increases plasma concentrations of eicosapentaenoic and docosahexaenoic acids in overweight and obese men and women. Nutr Res 2009, 29:609-615.

29. Flachs P, Mohamed-Ali V, Horakova O, Rossmeisl M, Hosseinzadeh-Attar MJ, Hensler M, Ruzickova J, Kopecky J: Polyunsaturated fatty acids of marine origin induce adiponectin in mice fed a high-fat diet. Diabetologia 2006, 49:394-397.

30. Awada M, Soulage CO, Meynier A, Debard C, Plaisancie P, Benoit B, Picard G, Loizon E, Chauvin MA, Estienne M, Peretti N, Guichardant M, Lagarde M, Genot C, Michalski MC: Dietary oxidized n-3 PUFA induce oxidative stress and inflammation: role of intestinal absorption of 4-HHE and reactivity in intestinal cells. J Lipid Res 2012, 53:2069-2080.

31. Chiang YF, Shaw HM, Yang MF, Huang CY, Hsieh CH, Chao PM: Dietary oxidised frying oil causes oxidative damage of pancreatic islets and impairment of insulin secretion, effects associated with vitamin $\mathrm{E}$ deficiency. Br J Nutr 2011, 105:1311-1319.

32. Michalski MC, Calzada C, Makino A, Michaud S, Guichardant M: Oxidation products of polyunsaturated fatty acids in infant formulas compared to human milk-a preliminary study. Mol Nutr Food Res 2008, 52:1478-1485.

33. Lefils J, Geloen A, Vidal H, Lagarde M, Bernoud-Hubac N: Dietary DHA: time course of tissue uptake and effects on cytokine secretion in mice. $\mathrm{Br} J$ Nutr 2010, 104:1304-1312.

34. Folch J, Lees M, Sloane Stanley GH: A simple method for the isolation and purification of total lipides from animal tissues. J Biol Chem 1957, 226:497-509.

35. Buttriss JL, Diplock AT: High performance liquid chromatogrphy methods for vitamin E in tissues. Methods Enzymol 1984, 105:131-138.

36. Etherton TD, Thompson EH, Allen CE: Improved techniques for studies of adipocyte cellularity and metabolism. J Lipid Res 1977, 18:552-557.

37. Calder PC: Polyunsaturated fatty acids, inflammatory processes and inflammatory bowel diseases. Mol Nutr Food Res 2008, 52:885-897.

38. Wan JB, Huang LL, Rong R, Tan R, Wang J, Kang JX: Endogenously decreasing tissue $n-6 / n-3$ fatty acid ratio reduces atherosclerotic lesions in apolipoprotein E-deficient mice by inhibiting systemic and vascular inflammation. Arterioscler Thromb Vasc Biol 2010, 30:2487-2494.

39. James MJ, Gibson RA, Cleland LG: Dietary polyunsaturated fatty acids and inflammatory mediator production. Am J Clin Nutr 2000, 71:343S-348S.

40. Krebs JD, Browning LM, McLean NK, Rothwell JL, Mishra GD, Moore CS, Jebb SA: Additive benefits of long-chain n-3 polyunsaturated fatty acids and weight-loss in the management of cardiovascular disease risk in overweight hyperinsulinaemic women. Int J Obes (Lond) 2006, 30:1535-1544.

41. Kiecolt-Glaser JK, Belury MA, Andridge R, Malarkey WB, Hwang BS, Glaser R: Omega-3 supplementation lowers inflammation in healthy middle-aged and older adults: A randomized controlled trial. Brain Behav Immun 2012, 26:988-995.

42. Laugerette F, Furet JP, Debard C, Daira P, Loizon E, Geloen A, Soulage CO, Simonet C, Lefils-Lacourtablaise J, Bernoud-Hubac N, Bodennec J, Peretti N, Vidal H, Michalski MC: Oil composition of high-fat diet affects metabolic inflammation differently in connection with endotoxin receptors in mice. Am J Physiol Endocrinol Metab 2012, 302:E374-E386.

43. Moreno-Navarrete JM, Manco M, Ibanez J, Garcia-Fuentes E, Ortega F, Gorostiaga E, Vendrell J, Izquierdo M, Martinez C, Nolfe G, Ricart W, Mingrone G, Tinahones F, Fernandez-Real JM: Metabolic endotoxemia and saturated fat contribute to circulating NGAL concentrations in subjects with insulin resistance. Int J Obes (Lond) 2010, 34:240-249.

44. Regueiro V, Campos MA, Morey P, Sauleda J, Agusti AG, Garmendia J, Bengoechea JA: Lipopolysaccharide-binding protein and CD14 are increased in the bronchoalveolar lavage fluid of smokers. Eur Respir $J$ 2009, 33:273-281.

45. Otero M, Lago R, Gomez R, Lago F, Gomez-Reino JJ, Gualillo O: Leptin: a metabolic hormone that functions like a proinflammatory adipokine. Drug News Perspect 2006, 19:21-26. 
46. Reseland JE, Haugen F, Hollung K, Solvoll K, Halvorsen B, Brude IR, Nenseter MS, Christiansen EN, Drevon CA: Reduction of leptin gene expression by dietary polyunsaturated fatty acids. J Lipid Res 2001, 42:743-750.

47. Ohashi K, Ouchi N, Matsuzawa Y: Anti-inflammatory and anti-atherogenic properties of adiponectin. Biochimie 2012, 94:2137-2142.

48. Warden $\mathrm{CH}$, Fisler JS: Comparisons of diets used in animal models of high-fat feeding. Cell Metab 2008, 7:277.10.1016/j.cmet.2008.03.014

49. Chen S, Subbaiah PV: Phospholipid and fatty acid specificity of endothelial lipase: potential role of the enzyme in the delivery of docosahexaenoic acid (DHA) to tissues. Biochim Biophys Acta 2007, 1771:1319-1328.

50. Hung ND, Kim MR, Sok DE: Oral administration of 2-docosahexaenoyl lysophosphatidylcholine displayed anti-inflammatory effects on zymosan A-induced peritonitis. Inflammation 2011, 34:147-160.

51. Lagarde M, Bernoud N, Brossard N, Lemaitre-Delaunay D, Thies F, Croset M, Lecerf J: Lysophosphatidylcholine as a preferred carrier form of docosahexaenoic acid to the brain. J Mol Neurosci 2001, 16:201-204. discussion 215-221.

52. Skurk T, Alberti-Huber C, Herder C, Hauner H: Relationship between adipocyte size and adipokine expression and secretion. J Clin Endocrinol Metab 2007, 92:1023-1033.

53. Esterbauer H, Schaur RJ, Zollner H: Chemistry and biochemistry of 4hydroxynonenal, malonaldehyde and related aldehydes. Free Radic Biol Med 1991, 11:81-128.

54. Esterbauer $\mathrm{H}$ : Cytotoxicity and genotoxicity of lipid-oxidation products. Am J Clin Nutr 1993, 57:779S-785S. Discussion 785S-786S.

55. Warnke MM, Wanigasekara E, Singhal SS, Singhal J, Awasthi S, Armstrong DW: The determination of glutathione-4-hydroxynonenal (GSHNE), E-4 -hydroxynonenal (HNE), and E-1-hydroxynon-2-en-4-one (HNO) in mouse liver tissue by LC-ESI-MS. Anal Bioanal Chem 2008, 392:1325-1333.

56. Esworthy RS, Yang L, Frankel PH, Chu FF: Epithelium-specific glutathione peroxidase, GPX2, is involved in the prevention of intestinal inflammation in selenium-deficient mice. J Nutr 2005, 135:740-745.

57. Wingler K, Muller C, Schmehl K, Florian S, Brigelius-Flohe R: Gastrointestinal glutathione peroxidase prevents transport of lipid hydroperoxides in CaCo-2 cells. Gastroenterology 2000, 119:420-430.

58. Choi SK, Zhang XH, Seo JS: Suppression of oxidative stress by grape seed supplementation in rats. Nutr Res Pract 2012, 6:3-8.

doi:10.1186/1743-7075-10-23

Cite this article as: Awada et al: $n-3$ PUFA added to high-fat diets affect differently adiposity and inflammation when carried by phospholipids or triacylglycerols in mice. Nutrition \& Metabolism 2013 10:23.

\section{Submit your next manuscript to BioMed Central and take full advantage of:}

- Convenient online submission

- Thorough peer review

- No space constraints or color figure charges

- Immediate publication on acceptance

- Inclusion in PubMed, CAS, Scopus and Google Scholar

- Research which is freely available for redistribution 